\title{
Effect of Carbonization and Multi-Walled Carbon Nanotubes on Polyacrylonitrile Short Carbon Fiber - Epoxy Composites
}

\author{
Vijay K. Srivastava, ${ }^{1}$ Nico Zamperlin, ${ }^{2}$ Bronwyn Fox, ${ }^{3}$ Alessandro Pegoretti ${ }^{2}$ \\ ${ }^{1}$ Department of Mechanical Engineering, Indian Institute of Technology (BHU), Varanasi, 221005, India \\ ${ }^{2}$ Department of Industrial Engineering, University of Trento, via Sommarive 9 I-38123, Trento, Italy \\ ${ }^{3}$ Institute for Frontier Materials, Deakin University, Geelong Waurn Pounds, Victoria, 3216, Australia
}

The present work deals with the characterization of multi-walled carbon nanotubes (MWCNTs) filled and unfilled short carbon fiber reinforced epoxy resin composites. Short carbon fibers $(10 \mathrm{~mm})$ were selected at various processing stages such as (i) white color polyacrylonitrile fibers (PAN); (ii) pre-carbonized carbon fibers (Precarb-CF); (iii) oxidized carbon fibers (OCF); (iv) fully carbonized carbon fibers (CF-low); and (v) sized carbon fibers (CF Sized). The investigated composites were characterized by three points bending test, hardness test, dynamic mechanical thermal analysis (DMTA), electrical conductivity test, thermogravimetric analysis (TGA), and scanning electron microscopy (SEM). The results show that the mechanical and electrical properties of the investigated materials markedly depend on the type of short carbon fibers and on the presence of MWCNTs. POLYM. COMPOS., 39:E817-E825, 2018. () 2016 Society of Plastics Engineers

\section{INTRODUCTION}

Carbon fibers are generally produced either by pyrolyzing fibers spun from polyacrylonitrile (PAN), or from pitch, or by chemical vapor deposition (CVD) [1]. The spinning method can only produce microscale carbon fibers (diameter $>5 \mu \mathrm{m}$ ) whereas carbon fibers with diameters ranging from micro to nano diameter can be synthesized through the CVD process [2]. Carbon and graphite materials are among the lightest structural materials; they have low density and thermal expansion, high thermal and electrical conductivity. They are considered as attractive materials for high-temperature applications because they have high strength and stiffness above 2,500 K [3]. Carbon fibers can be produced with desirable

Correspondence to: V.K. Srivastava; e-mail: vijayks210@gmail.com DOI 10.1002/pc.24252

Published online in Wiley Online Library (wileyonlinelibrary.com).

(C) 2016 Society of Plastics Engineers strength-to-weight properties; they are finding increased structural uses in fields such as aerospace, aeronautical, and sporting goods applications. At an industrial level, carbon fibers are generally produced from various materials such as polyacrylonitrile (PAN), pitch $[4,5]$, rayon [6], cellulose [5], and phenolic resins [7, 8]. Optimum stabilized PAN fibers can produce higher modulus carbon fibers. If the stabilizing temperature is excessively high, the fibers can overheat and burn. However, too low stabilizing temperature will lead to an incomplete yield and poor quality [9]. The carbonization process only occurs in inert atmosphere. In the first stage, the carbonization process is carried out via thermal pyrolysis up to $600^{\circ} \mathrm{C}$ at a lower heating rate $\left(5^{\circ} \mathrm{C} / \mathrm{min}\right)$ and the second stage with high heating rate. An optimum carbonization temperature is required to form a carbon fiber with the desired properties $[10,11]$.

Recently, carbon nanotubes received an increased attention because of their potential application as reinforcement for composite materials, in high temperature catalysis and in components for nanoelectronics and photonics $[12,13]$. The main advantage of nanocomposites over microcomposites lies in the improvement of performance that often acquired at a low percentage of nanofillers. The remarkable improvements in mechanical and electrical properties of nanocomposites are achieved due to the increase of surface to volume ratio and atomic surface interaction with the matrix [14, 15]. Carbon nanotubes have been proven to improve the flexural modulus and strength of polymer matrices even when dispersed in very low amounts [16-19]. Therefore, addition of nanoparticles in conventional carbon fiber reinforced composites improves the mechanical and electrical properties [20-23]. Synergistic effects of the addition of nanofillers to polymer matrices have been also observed in glassfiber reinforced polymers as recently reported [24-27]. 
The main objective of this study is to compare the mechanical, electrical, and thermal properties of multiscale micro-nano epoxy composites containing both multi-walled carbon nanotubes (MWCNTs) and short carbon fibers. Short carbon fibers were used in different forms including, white color polyacrylonitrile carbon fibers (PAN), pre-carbonized carbon fibers (Precarb-CF), oxidized carbon fibers (OCF), fully carbonized carbon fibers (CF-low), and sized carbon fibers (CF Sized). The authors are not aware of similar studies in which the effect of short fibers at various stages of their path from a polymeric (PAN) to a fully carbonized structure (CF) have been compared. The investigated materials were characterized through mechanical testing like, flexural (3points bending), hardness, dynamic mechanical thermal analysis (DMTA), thermogravimetric analysis (TGA), electrical testing, and morphological observation by scanning electron microscope (SEM) analysis.

\section{EXPERIMENTAL}

\section{Materials and Specimens}

Polyacrylonitrile (PAN) based carbon fiber was obtained from Carbon Nexus, Institute of Frontier Materials, Deakin University, Geelong, Victoria, Melbourne, Australia. Carbon Nexus is a globally unique carbon fiber and composite research facility owned and operated by Deakin University. At Carbon Nexus, carbon fibers were produced from polyacrylonitrile (PAN) fibers. The polymer was converted into carbon at extremely high temperatures. Initially, PAN precursor was spun into filament yarns, using chemical and mechanical processes. At this stage, the yarns consist of super fine white continuous fibers with an average diameter of about $10 \mu \mathrm{m}$. The spun PAN fibers are therefore stabilized through oxidation, which converts their linear structure to a more thermally stable ladder structure. This was achieved by heating the fibers to a temperature of $300^{\circ} \mathrm{C}$ for up to 120 min in an oven. After stabilization, the fibers were carbonized. This involved heating them up to $3,000^{\circ} \mathrm{C}$ in the presence of an inert gas (e.g. nitrogen) in a furnace. Extreme heat treatment causes the fibers to expel all noncarbon atoms and form tightly bonded carbon crystals that are aligned more or less parallel to the axis of the fiber. To create better chemical bonding properties, the surface was slightly oxidized by an electrolytical treatment. Fibers were then washed, dried, and coated to protect them from damage before they were wound onto bobbins.

In this work, short carbon fibers (10 mm length) were selected among (i) original polyacrylonitrile fibers (PAN); (ii) pre-carbonized PAN carbon fibers (Precarb-CF), (iii) oxidized carbon fibers (OCF); (iv) fully carbonized carbon fibers (CF-low); and (v) sized carbon fibers (CF Sized). Multi-walled carbon nanotube (MWCNT) was used as filler materials, which was obtained from J.K. Impex Company, Mumbai with $99.5 \%$ purities. The main
TABLE 1. Main geometrical features and elastic moduli of the selected constituents.

\begin{tabular}{llc}
\hline Materials & \multicolumn{1}{c}{ Geometry } & $\begin{array}{c}\text { Elastic } \\
\text { modulus }(\mathrm{GPa})\end{array}$ \\
\hline MWCNT & Length $= \pm 2 \mu \mathrm{m}$ & 1,000 \\
$99.98 \%$ & Average Inner diameter $= \pm 6.5 \mathrm{~nm}$ & \\
& Average Outer diameter $= \pm 40 \mathrm{~nm}$ & 2.0 \\
Epoxy resin & $-\quad$ & 200 \\
PAN & Diameter $=\sim 10 \mu \mathrm{m}$, length $=10 \mathrm{~mm}$ & $200-280$ \\
Precarb-CF & Diameter $=\sim 10 \mu \mathrm{m}$, length $=10 \mathrm{~mm}$ & $280-350$ \\
OCF & Diameter $=\sim 7.0 \mu \mathrm{m}$, length $=10 \mathrm{~mm}$ & $350-600$ \\
CF low & Diameter $=\sim 7 \mu \mathrm{m}$, length $=10 \mathrm{~mm}$ & 600 \\
CF sized & Diameter $=\sim 7 \mu \mathrm{m}$, length $=10 \mathrm{~mm}$ & \\
\hline
\end{tabular}

geometrical features and elastic moduli of the selected reinforcing materials are summarized in Table 1.

Epoxy resin was obtained from Ciba-Geigy Ltd., Mumbai. The araldite (LY-556) 55\%, hardener (HY-917) 49\%, and accelerator (DY-070) $0.28 \%$ were used to crosslink the epoxy resin. Shen et al. reported that a weight content of MWCNTs lower than $1 \%$ was enough to improve the mechanical properties of an epoxy resin [18]. Therefore, $0.5 \%$ MWCNT filler was selected as weight percentage. MWCNT filled epoxy resin was homogenized using a labscale three-roll-mill (Exakt 120 EXAKT Advanced Technology $\mathrm{GmbH}$, Germany), which enables the introduction of very high shear rates (up to $200,000 \mathrm{~s}^{-1}$ ) throughout the suspension. The pre-dispersed suspension was then passed through the rolls with dwell times of $2 \mathrm{~min}$. The dispersive forces on the suspension were acting in a very thin gap $(5 \mu \mathrm{m})$ between the rolls. After dispersion of the MWCNT in the resin LY-556, the hardener and accelerator were added in a vacuum dissolver, in order to remove trapped air from the suspension. Then the mixture was placed in a vacuum chamber for $20 \mathrm{~min}$ to eliminate the bubbles introduced during the rolling process. The dispersed mixtures of MWCNT and resin were subsequently diluted by adding the hardener (HY-917) in a weight ratio with the epoxy resin of 10:1. MWCNT/epoxy resin mixture was mixed by the same method described above to remove air bubbles before curing. Simultaneously, short carbon fibers in a weight percentage of $2.34 \%$ were added to the mixture of MWCNT and epoxy resin matrix and properly stirred for 2 min. Then mixtures were poured in a silicon mold and allow to cure at room temperature for $24 \mathrm{~h}$. After curing, specimens were machined as per the ASTM D-790-10 standard for the measurement of mechanical properties. The details of sample are listed in Table 2.

\section{Flexural Test}

Three point flexural tests were conducted on an Instron 4502 machine equipped with a $10 \mathrm{kN}$ load cell operating at a strain rate of $0.01 \mathrm{~min}^{-1}$. The specimen's dimensions were selected according to ASTM D-790-10 standard and a span length of $80 \mathrm{~mm}$ was adopted. 
TABLE 2. Details of sample coding and composition.

\begin{tabular}{|c|c|}
\hline Composition & Sample coding \\
\hline $\begin{array}{l}\text { CF Low }(2.34 \%), \text { MWCNT }(0.5 \%), \\
\text { Epoxy resin }(97.16 \%)\end{array}$ & CF-Low_with-CNT \\
\hline CF Low $(2.34 \%)$, Epoxy resin $(97.66 \%)$ & CF-Low_no-CNT \\
\hline $\begin{array}{l}\text { CF Sized }(2.34 \%), \text { MWCNT }(0.5 \%) \\
\quad \text { Epoxy resin }(97.16 \%)\end{array}$ & CF-Sized_with-CNT \\
\hline CF Sized (2.34\%), Epoxy resin $(97.66 \%)$ & CF-Sized_no-CNT \\
\hline $\begin{array}{l}\text { OCF }(2.34 \%), \text { MWCNT }(0.5 \%) \\
\text { Epoxy resin }(97.16 \%)\end{array}$ & OCF_with-CNT \\
\hline OCF $(2.34 \%)$, Epoxy resin $(97.66 \%)$ & OCF_no-CNT \\
\hline $\begin{array}{l}\text { Precarb-CF }(2.34 \%), \text { MWCNT }(0.5 \%) \\
\quad \text { Epoxy resin }(97.16 \%)\end{array}$ & Precarb-CF_with-CNT \\
\hline Precarb-CF $(2.34 \%)$, Epoxy resin $(97.66 \%)$ & Precarb-CF_no-CNT \\
\hline $\begin{array}{l}\text { PAN }(2.34 \%), \text { MWCNT }(0.5 \%) \\
\quad \text { Epoxy resin }(97.16 \%)\end{array}$ & PAN_with-CNT \\
\hline PAN $(2.34 \%)$, Epoxy resin $(97.66 \%)$ & PAN_no-CNT \\
\hline
\end{tabular}

The cross-head speed was measured to the given equation [7]

$$
\mathrm{R}=\frac{\mathrm{ZL}^{2}}{6 \mathrm{~d}}
$$

where $\mathrm{R}$ is the rate of cross-head speed $\left(\mathrm{mm} \mathrm{min}^{-1}\right), \mathrm{L}$ is the span distance $(\mathrm{mm}), \mathrm{d}$ is the depth of beam $(\mathrm{mm})$, and $\mathrm{Z}$ is the strain rate $\left(\mathrm{min}^{-1}\right)$.

To simplify the analysis, the maximum stress was calculated at the midpoint of the specimen even if the fracture occurred in a different location. The flexural stress at midpoint was calculated with the following equation:

$$
\sigma_{\mathrm{f}}=\frac{3 \mathrm{PL}}{2 \mathrm{bd}^{2}}
$$

where $\mathrm{P}$ is the maximum load at midpoint $(\mathrm{N}), \mathrm{L}$ is the span distance $(\mathrm{mm}), \mathrm{d}$ is the depth of beam $(\mathrm{mm}), \mathrm{b}$ is the width of beam $(\mathrm{mm})$, and $\sigma_{\mathrm{f}}$ is the stress in the outer fibers at midpoint $(\mathrm{MPa})$.

The tangent slope (m) of the initial part of loadcrosshead motion plot was used to evaluate the flexural modulus (E) according to the following equation:

$$
E=\frac{L^{3} m}{4 b d^{3}}
$$

where $\mathrm{m}$ is the initial slope of load - displacement graphics. The arithmetic mean and standard deviation were calculated on at least three specimens for each sample.

\section{Hardness Test}

Vicker's hardness was determined by a LV 700AT testing machine (Gund Company, Germany). The hardness testing machine was provided with a diamond indenter having a vertex angle of $136^{\circ}$. A load of $5 \mathrm{~kg}$ was applied for duration of $30 \mathrm{sec}$. To eliminate any possible segregation effect, a total of five readings were taken for every sample at different locations.
Dynamic Mechanical Thermal Analysis (DMTA)

Dynamic mechanical thermal analysis (DMTA) tests were performed by a DMA Q800 machine by TA Instruments. Glass transition temperature $(\mathrm{Tg})$, storage modulus $\left(E^{\prime}\right)$, loss modulus $\left(E^{\prime \prime}\right)$, and loss tangent $\left(\tan \delta=E^{\prime \prime} / E^{\prime}\right)$ of all composite specimens were determined under tensile mode. All tests were performed in a temperature range from $25^{\circ} \mathrm{C}$ to $150^{\circ} \mathrm{C}$, at a heating rate of $3^{\circ} \mathrm{C} / \mathrm{min}, 10 \mathrm{~Hz}$ frequency, and $0.05 \%$ strains. The distance between clamps was fixed $10-12 \mathrm{~mm}$ and specimen thickness $2.5 \mathrm{~mm}$ and width 4.5 to $6.0 \mathrm{~mm}$.

\section{Electrical Test}

A Keithley 6517A electrometer was used to measure the electrical resistance according to ASTM D4496-04 standard. Measurements were made between two points at a distance of $19.1 \mathrm{~mm}$ with potential difference of $5 \mathrm{~V}$. The volume resistivity $(\Omega \mathrm{cm})$ was calculated using Ohm's law of each specimen. Volumetric resistivity $\left(\rho_{V}\right)$ can be estimated using the following equation [11]:

$$
\rho_{\mathrm{V}}=\frac{\Delta \mathrm{Vwt}}{\mathrm{IL}}
$$

where $\mathrm{w}$ is the width of the specimen, $\mathrm{t}$ is the thickness of the specimen, $\mathrm{L}$ is the length of the specimen, $\Delta \mathrm{V}$ is the electrical potential difference, and I is the current.

\section{Thermogravimetric Test}

Thermogravimetric analysis (TGA) tests were performed with a TA Instrument Q5000 IR device. Measurements were performed at a heating rate of $10^{\circ} \mathrm{C} / \mathrm{min}$ up to $800^{\circ} \mathrm{C}$ under a nitrogen flux.

\section{Scanning Electron Microscopy Test}

Scanning electron microscopy (SEM) observations were performed by a Supra 40 field emission scanning electron microscope (FESEM, Carl Zeiss AG) on the fracture surfaces of the specimens broken under three-points bending tests. Observations were conducted under vacuum $\left(10^{-5}-10^{-6}\right.$ torr $)$ at an acceleration voltage of $5 \mathrm{kV}$ and at various magnifications.

\section{RESULTS AND DISCUSSION}

\section{Effect of MWCNTs on Flexural Strength and Modulus}

Flexural strength and elastic modulus of individual MWCNTs filled short carbon fiber reinforced epoxy resin composites were measured under three point flexural tests and the obtained data reported in Fig. 1. The results clearly indicate that the flexural strength (Fig. 1a) and elastic modulus (Fig. 1b) of composites CF-Low, CF-Sized, $\mathrm{OCF}$, Precarb-CF, and PAN were all increased by the 

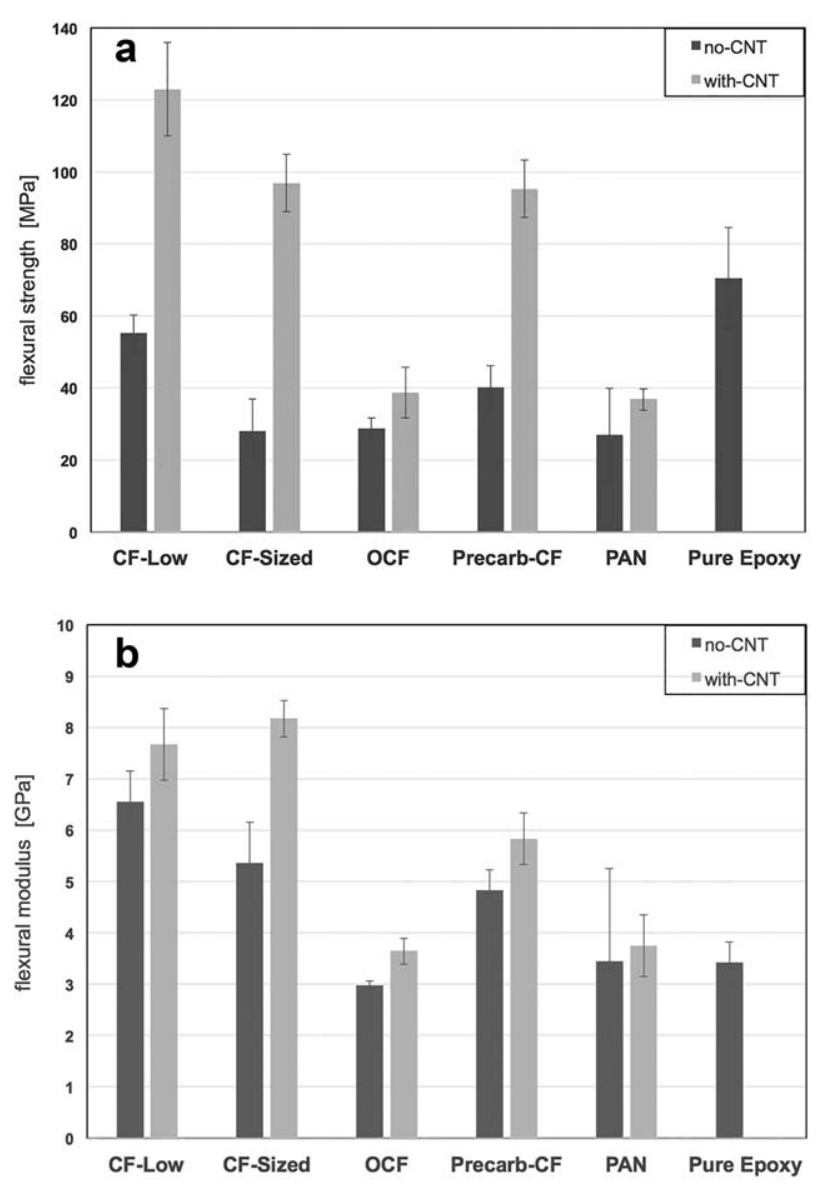

FIG. 1. Variation of (a) flexural strength and (b) flexural modulus of the investigated composites.

addition of $0.5 \mathrm{wt} \%$ MWCNTs. Specifically, the flexural strength and elastic modulus of CF-Low composite increased from 55.2 $\mathrm{MPa}$ to $123.0 \mathrm{MPa}$ and $6.55 \mathrm{GPa}$ to 7.67 GPa by addition of MWCNTs. The flexural strength and elastic modulus of CF-sized composite increased from 28.0 $\mathrm{MPa}$ to $96.9 \mathrm{MPa}$ and 5.35 $\mathrm{GPa}$ to $8.17 \mathrm{GPa}$ by addition of MWCNTs filler. The flexural strength and elastic modulus of OCF composite increased from 28.7

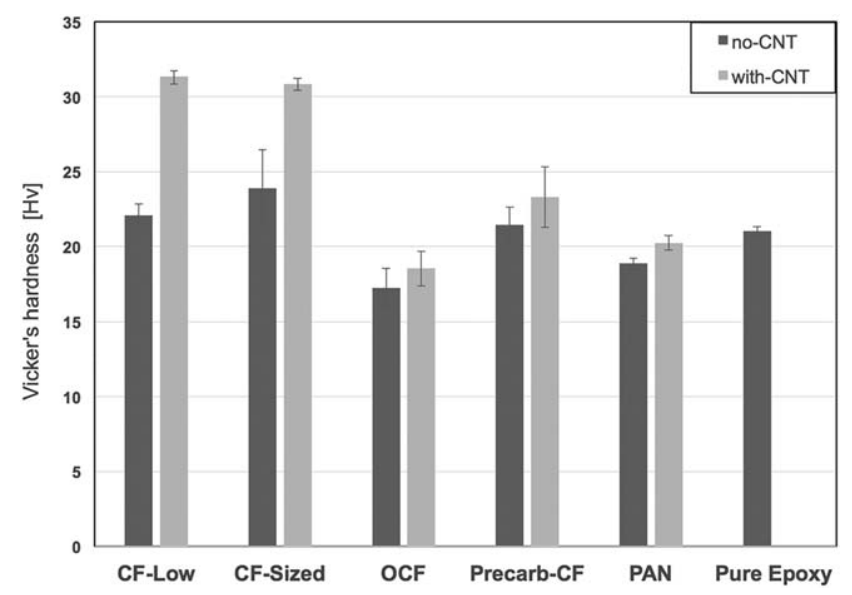

FIG. 2. Variation of Vicker's hardness of the investigated composites.

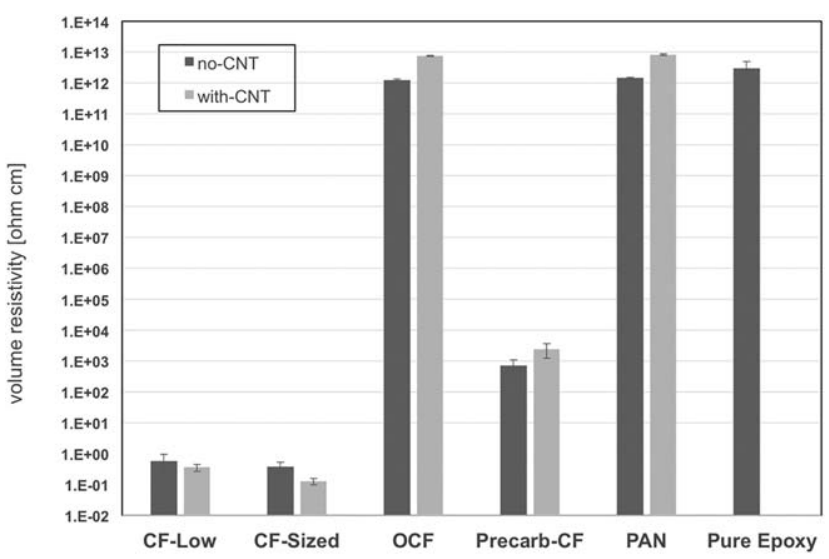

FIG. 3. Variation of volumetric resistivity of the investigated composites.

$\mathrm{MPa}$ to $38.7 \mathrm{MPa}$ and $2.98 \mathrm{GPa}$ to $3.64 \mathrm{GPa}$ by addition of MWCNTs filler. The flexural strength and elastic modulus of Precarb-CF composite increased from $40.2 \mathrm{MPa}$ to $95.3 \mathrm{MPa}$ and $4.83 \mathrm{GPa}$ to $5.83 \mathrm{GPa}$ by addition of MWCNTs filler. The flexural strength and elastic modulus of PAN composite increased from 26.9 $\mathrm{MPa}$ to 36.8 $\mathrm{MPa}$ and $3.45 \mathrm{GPa}$ to $5.83 \mathrm{GPa}$ by addition of MWCNTs filler. It is worthwhile to note that flexural strength (70.6 $\mathrm{MPa}$ ) and elastic modulus (3.42 GPa) of epoxy resin was lower than the MWCNTs filler loaded CF-Low, CFSized, and OCF composites. As reported in Fig. 2, The Vicker's hardness of all investigated samples increased with the presence of MWCNT. The increased hardness of MWCNTs filled short carbon fiber composites may be due to the presence of MWCNTs reinforcements that may act as constraint to localized deformation during indentation. The strengthening of MWCNTs in short carbon fiber epoxy resin composite is associated with basic mechanisms including load transfer from matrix to MWCNTs [8], mismatch in coefficient of thermal expansion [13], and Orowan looping [17]. Generally, MWCNT increases the toughness of epoxy resin as well as fiber

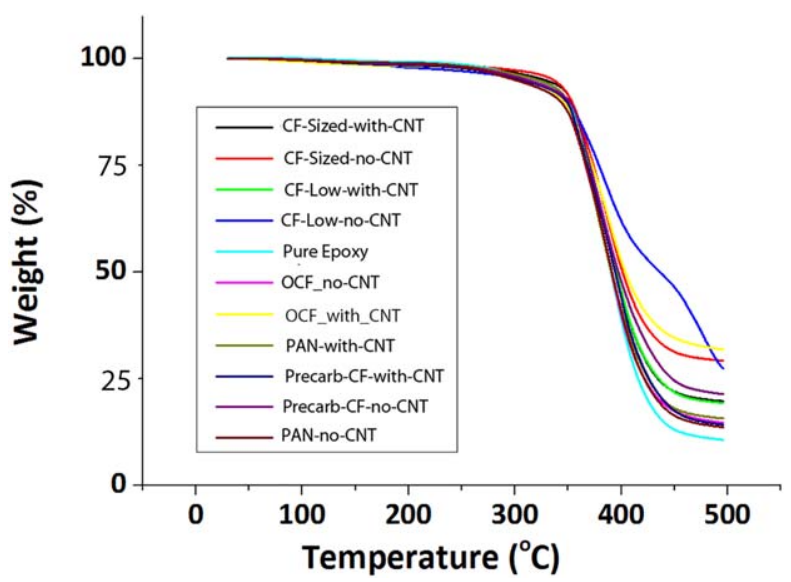

FIG. 4. Thermogravimetric curves of the investigated composites. 

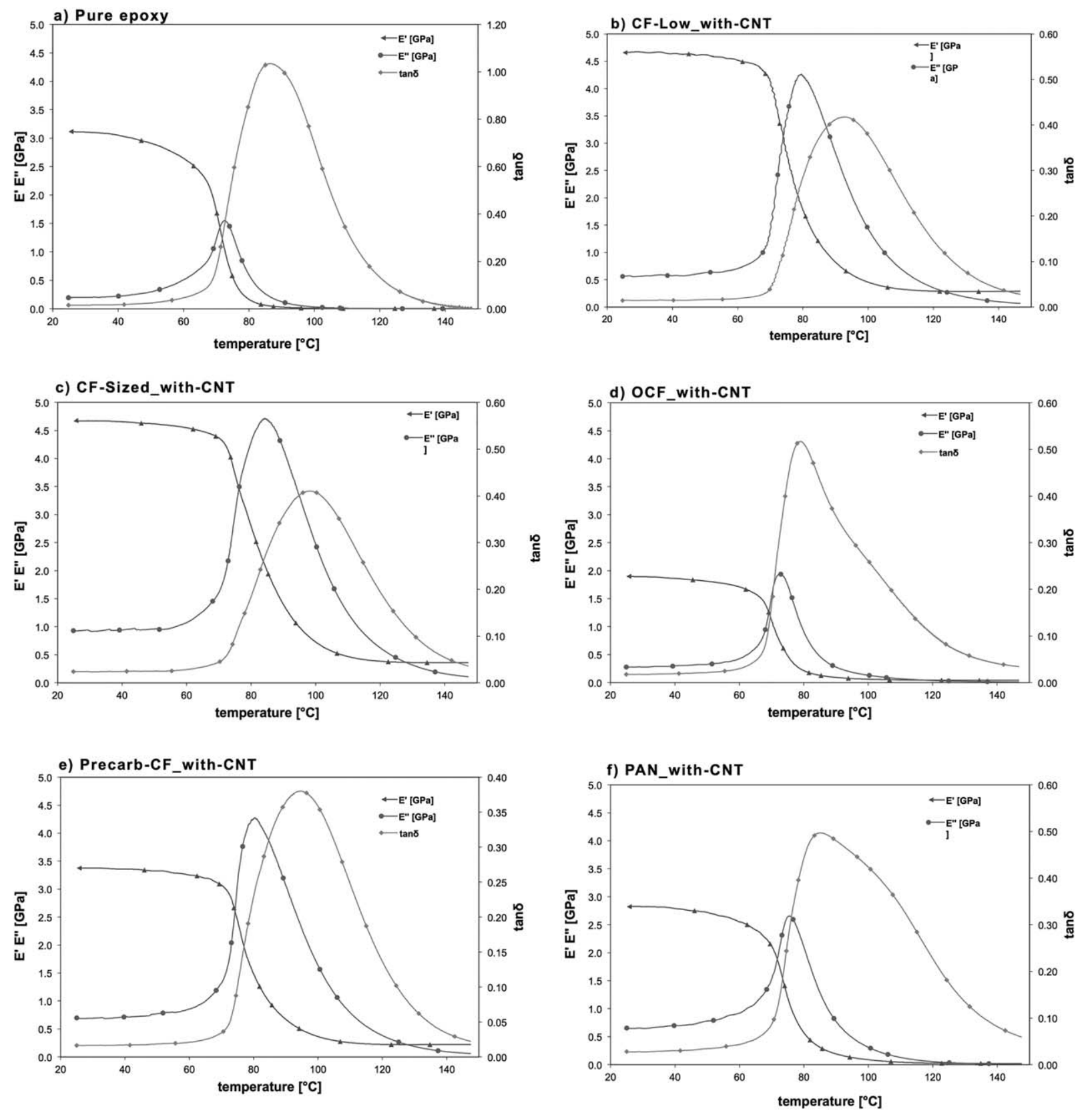

FIG. 5. Variation of storage modulus, loss modulus, and tan $\delta$ with temperature of (a) pure epoxy, (b) CFLow_with-CNT, (c) CF-Sized_with-CNT, (d) OCF_with-CNT, (e) Precarb-CF_with-CNT, (f) PAN_with-CNT, (g) CF-Low_no-CNT, (h) CF-Sized_no-CNT, (i) OCF_no-CNT, (j) Precarb-CF_no-CNT, and (k) PAN_no-CNT.

composites [12]. However, the efficiency of fillers against fracture depends on their distribution in the matrix, volume fraction, and orientation of nano-fillers/ short carbon fiber [15].

\section{Effect of MWCNTs on Electrical Resistivity}

The electrical resistivity is an intrinsic property that quantifies how strongly a given material opposes the flow of electric current. A low resistivity indicates a material that readily allows the movement of electric charges [11]. Figure 3 shows that volumetric resistivity of CF-Low,
CF-Sized, and Precarb-CF samples is much lower than that of neat epoxy and that of OCF and PAN samples. These results clearly depend on the electrically conductive behavior of precarbonized and fully carbonized fibers in contrast to the insulating nature of OCF and PAN fibers. It can also be observed that the volume resistivity decreased with the addition of MWCNTs. This effect is clearly due to the elevated electrical conductivity values of carbon nanotubes. Moreover, they could form electrically conductive bridges between short carbon fiber thus establishing good conductive paths through the composite structure. 

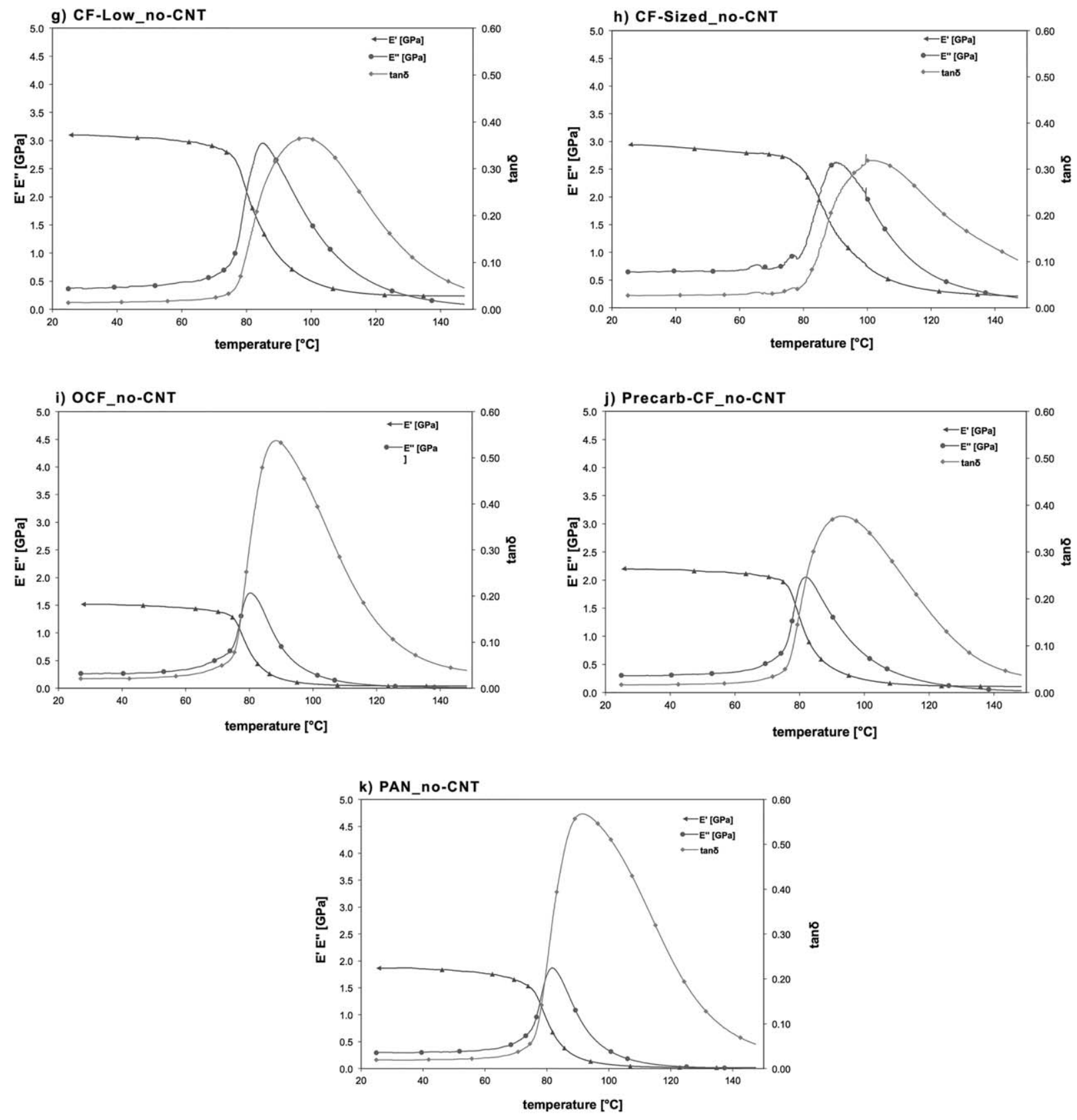

FIG. 5. (Continued).

\section{Effect of MWCNT on Thermal Stability}

The thermal stability of the investigated MWCNT filled and unfilled short carbon fiber epoxy resin composites were investigated by thermogravimetric analysis (TGA). It is clear that the dispersion of nanoparticles and short carbon fibers in the epoxy resin will significantly change the properties of nano filled short carbon fiber composites. Figure 4 exhibits the TGA curves of the neat epoxy resin, MWCNT filled short carbon fiber epoxy resin and unfilled MWCNT short carbon fiber epoxy resin composites. All TGA curves of different types of composites present similar trend of decomposition process. Significant weight loss occurred in all samples above $350^{\circ} \mathrm{C}$. Minor weight loss below this temperature is attributed to the elimination of absorbed water, release of hydroxyl groups and oxidation of amorphous carbon. The decomposition region is centered between, $250-480^{\circ} \mathrm{C}$. It was observed that when MWCNTs are added to the epoxy resin filled and unfilled with short carbon fiber, TGA curves manifested lower weight losses compared to neat epoxy resin. The rightward shift of TGA curve of composite indicates improved thermal stability, which may be due to the improved dispersion of MWCNTs and short carbon fiber [10], while the leftward shift of TGA curve of composites proves a decreased thermal stability. This may be due to the aggregation of MWCNT particles and short carbon fiber in composites. 

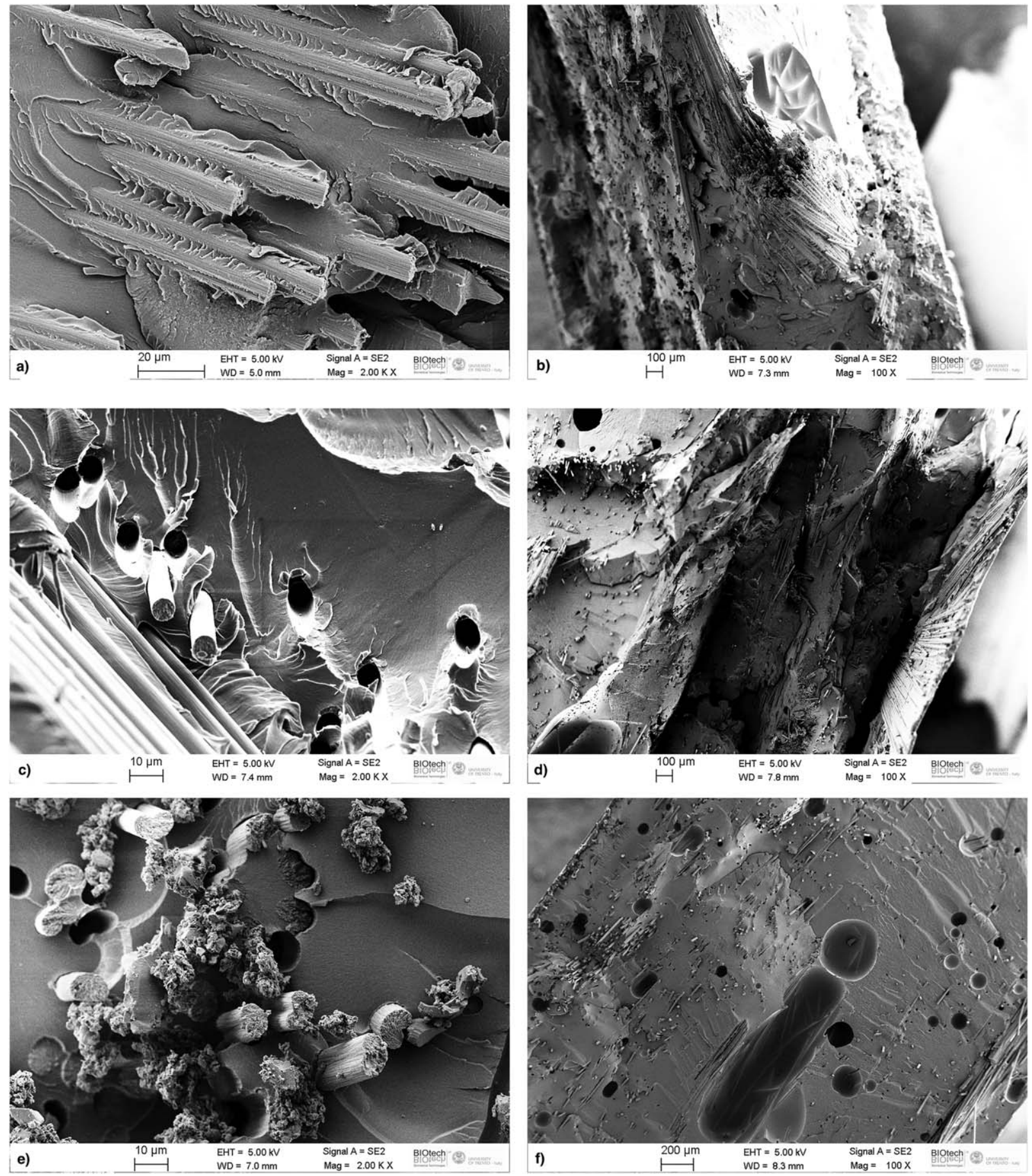

f)

$W D=8.3 \mathrm{~mm}$

FIG. 6. SEM observations on (a) CF-Low_no-CNT, (b) CF-Low_with-CNT, (c) CF-Sized_no-CNT, (d) CFSized_with-CNT, (e) OCF_no-CNT (f) OCF_with-CNT, (g) Precarb-CF_no-CNT (h) Precarb-CF_with-CNT, (i) PAN_no-CNT, and (j) PAN_with-CNT.

\section{Effect of MWCNT on Dynamic Mechanical Behavior}

The DMTA plots of MWCNT filled and unfilled short carbon fiber epoxy resin composites are illustrated in Fig. 5 where the storage modulus $\left(\mathrm{E}^{\prime}\right)$, loss modulus $\left(\mathrm{E}^{\prime \prime}\right)$, and $\tan \delta$ are plotted as a function of temperature. Figure 5a shows the DMTA thermogram of pure epoxy resin. The observed behavior is typical for an amorphous polymer with a transition from a glassy to a rubbery state as the temperature rises. Its glass transition temperature, estimated in correspondence of the maximum value of the loss tangent, is of $86.4^{\circ} \mathrm{C}$. The MWCNT filled short carbon fiber epoxy resin curves (Figs. 5b-f) are compared with the short carbon fiber epoxy resin composites without MWCNT (Figs. 5g-k). The glass transition temperature (Tg) is determined from the peak position of tan $\delta$ peak. These results clearly indicate that the MWCNT fillers 

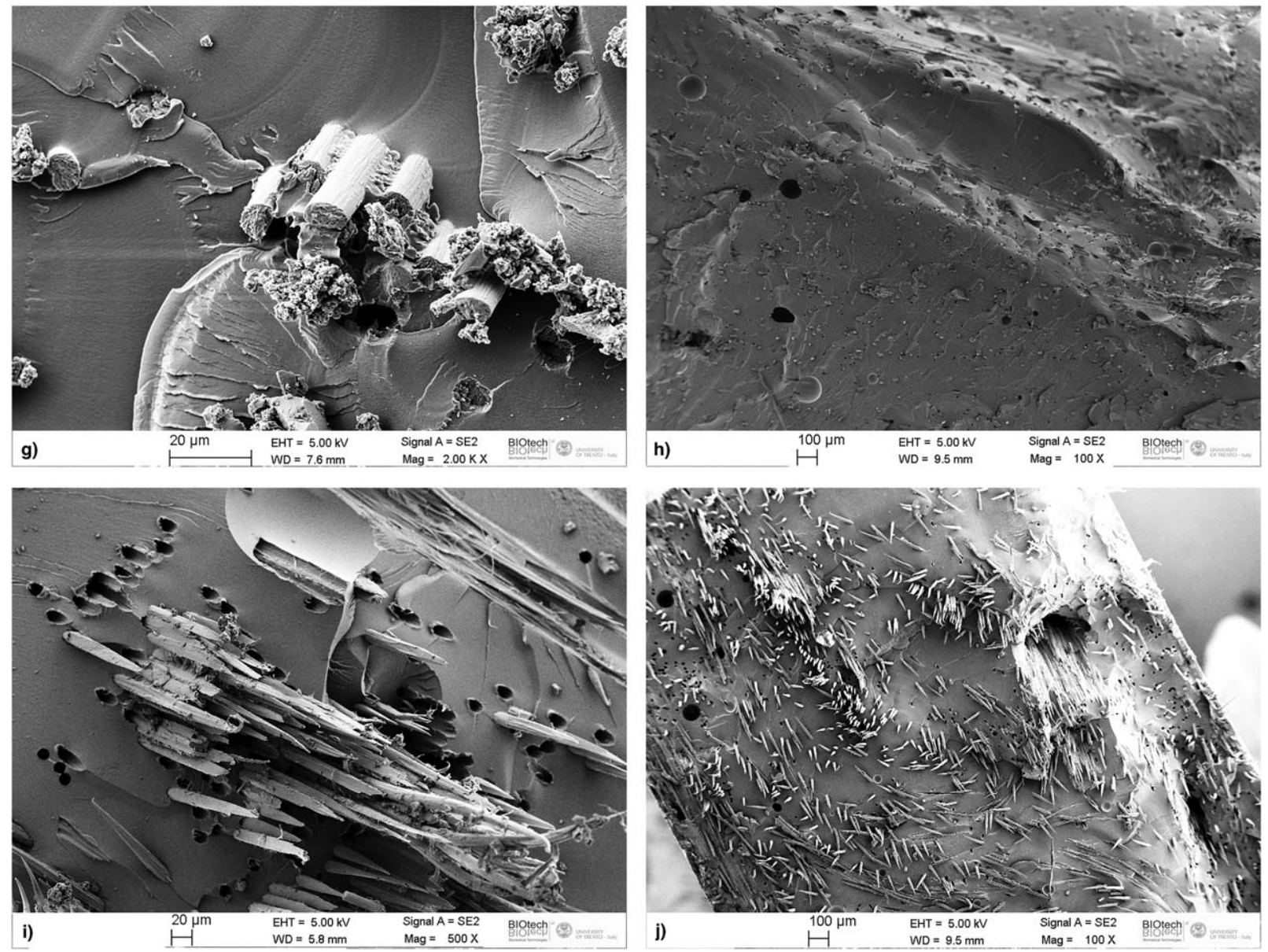

FIG. 6. (Continued).

caused minor effects on the Tg. MWCNT filled CF-Low, CF-Sized, OCF, Precarb-CF, and PAN manifest lower values of $\mathrm{Tg}$ in comparison to the corresponding composites without MWCNT. The presence of nanotubes may increase the number of agglomerations and thus the empty spaces in the short carbon fiber composite network [5], which results in lower $\mathrm{Tg}$ values. Nevertheless, it is worthwhile to note that the literature indications on the effects of MWCNT on the curing reaction of epoxy resins are widespread and contradictory [28] and they do not allow one to isolate the effect of MWCNT on the glass transition [29].

In the case of CF-Low, CF-Sized the presence of short fibers and MWCNT plays a synergistic and beneficial effect on the storage modulus with a remarkable increase of its value in the glassy state.

\section{SEM Observations}

Figure 6 shows the SEM image of the MWCNT filled and unfilled short carbon fiber epoxy resin composite. Figure 6a shows the strong interfacial bond in between fiber and matrix in CF-Low, in which fibers are mostly broken and surrounded by matrix. Micro cracks are also detectable in the matrix. Figure $6 \mathrm{~b}$ depicts the blow holes and irregular surfaces due to the high viscosity of epoxy resin, which limited the movement of the nanotubes and prevented the proper distribution of them throughout the resin. In Fig. 6c, the fracture surface of CF-Sized_noCNT sample is reported in which the random distribution of carbon fiber can be noticed, along with the occurrence of fiber pull-out and fiber breakage phenomena. A quite uniform distribution of nanotubes in short carbon fiber epoxy resin composite was observed due to bundling of carbon fiber and nanotubes as shown in Fig. 6d. Figure 6e indicates that the OCF sample has a different structure, presenting the lowest compressive load, Vicker's hardness and viscoelastic properties in comparison to CF-Low and CF-Sized samples. Figure $6 f$ indicates that $\mathrm{OCF}_{-}$withCNT sample contains blow holes in the resin reach area due to the thermal expansion of the fiber and matrix. The micrograph shows the epoxy resin fracture in different direction and cracks debond the Precarb-CF sample as can be seen from Fig. 6g. It is clear that MWCNT particles well dispersed in the epoxy resin matrix as can be identified from Fig. 6h. The fracture surface of sample PAN_no-CNT shows that the bundles of short PAN fiber are broken at a different length and some fibers are pulled out from the matrix as can be observed from the Fig. 6i and $6 \mathrm{j}$, which indicates good and bad adhesion between the epoxy resin and carbon fiber in different area. 
Based on the SEM images, one can observe that uniform dispersion and perfect adhesion of short carbon fiber and MWCNTs in the epoxy resin are the main reasons for an increase of the mechanical and electrical properties of epoxy resin $[9,11]$. Perfect interfacial bonding is fully transferring the effective stress from epoxy resin to short carbon fiber and MWCNTs. Short carbon fiber reinforced epoxy resin composite generally fails in various modes including delamination, fiber pull-out, and fiber breakage, where MWCNT filled short fiber reinforced epoxy resin fails mostly in fiber-breaking mode due to high interface bond strength. This reveals that the great effect of MWCNTs surface groups on the interfacial bonding. However, quality of carbon fiber may also affect the bonding strength of composites [4].

\section{CONCLUSIONS}

The addition of MWCNTs affects the mechanical properties of all type of investigated short carbon fiber reinforced epoxy resin composites. The flexural strength, elastic modulus, and Vicker's hardness of MWCNTs filled and unfilled CF-Low and CF-Sized samples are higher than that of OCF, Precarb-CF, and PAN composites. The volumetric resistivity values of MWCNTs filled and unfilled CF-Low and CF-Sized and Precarb-CF composites are much lower than that of neat epoxy matrix and other composites. The TGA curves of all composite indicate a thermal stability better than that of pure epoxy resin because of the improved dispersion of MWCNTs and short carbon fiber. All MWCNT filled samples present lower values of $\mathrm{Tg}$ compared to MWCNT unfilled samples. A possible reason for the observed $\mathrm{Tg}$ reduction could be that nanotubes bundles attract epoxy functional groups in their local vicinity and prevent them from reacting with the amine groups of the hardener during the cure process. However, the significant enhancement of properties in short carbon fiber reinforced epoxy resin is distinctively due to the effect of MWCNTs filler. The addition of MWCNT fillers improves the toughness hindering the microcracks formation in epoxy resin.

\section{ACKNOWLEDGMENTS}

The University of Trento is greatly acknowledged for supporting the one-month visiting professor position of VKS.

\section{REFERENCES}

1. E. Fitzer and M. Heine, "Carbon fiber manufacture and surface treatment," in Fiber Reinforcements for Composite Materials, R. Bunsell, Ed., Elsevier, Amsterdam, 73 (1988).

2. D.D. Edie and M.G. Dunham, Carbon, 27, 647 (1989).
3. M.C. Paiva, C.A. Bernardo, and M. Nardin, Carbon, 38, 1323 (2000).

4. R.J. Smiley and W.N. Delgass, J. Mater. Sci., 28, 3601 (1993).

5. O. Duman and E. Ayranci, Separ. Sci. Technol., 41, 3673 (2006).

6. E. Ayranci and O. Duman, Separ. Sci. Technol., 44, 3735 (2009).

7. O. Duman and E. Ayranci, J. Hazard. Mater., 176, 231 (2010).

8. O. Duman and E. Ayranci, J. Hazard. Mater., 174, 359 (2010).

9. M.C. Paiva, M. Nardin, C.A. Bernardo, and J. Schultz, Compos. Sci. Technol., 57, 839 (1997).

10. S.B. Hanna, A.A. Yehia, M.N. Ismail, and A.I. Khalaf, $J$. Appl. Polym. Sci., 123, 2074 (2012).

11. W.X. Zhang, J. Liu, and G. Wu, Carbon, 41, 2805 (2003).

12. D.K. Seo, J.P. Jeun, H. Bin Kim, and P.H. Kang, Rev. Adv. Mater. Sci., 28, 31 (2011).

13. E. Zussman, X. Chen, W. Ding, L. Calabri, D.A. Dikin, J.P. Quintana, and R.S. Ruoff, Carbon, 43, 2175 (2005).

14. A. Lonjon, P. Demont, E. Dantras, and C. Lacabanne, J. Non-Cryst. Solids, 358, 1859 (2012).

15. G.B. Zheng, K. Kouda, H. Sano, Y. Uchiyama, Y.F. Shi, and H.J. Quan, Carbon, 42, 635 (2004).

16. Q.F. Cheng, J.P. Wang, J.J. Wen, C.H. Liu, K.L. Jiang, Q.Q. Li, and S.S. Fan, Carbon, 48, 260 (2010).

17. M. Dehghan, R. Al-Mahaidi, and I. Sbarski, Int. J. Chem. Mol. Nucl. Mater. Metallurg. Eng., 8, 113 (2014).

18. J. Shen, W. Huang, L. Wu, Y. Hu, and M. Ye, Compos. Sci. Technol., 67, 3041 (2007).

19. S. Singh, V.K. Srivastava, and R. Prakash, Appl. Nanosci., 5, 305 (2015).

20. G. Bussu and A. Lazzeri, J. Mater. Sci., 41, 6072 (2006).

21. J.N. Coleman, U. Khan, W.J. Blau, and Y.K. Gun'ko, Carbon, 44, 1624 (2006).

22. C. McClory, T. McNally, G.P. Brennan, and J. Erskine, $J$. Appl. Polym. Sci., 105, 1003 (2007).

23. V.K. Srivastava, Mater. Des., 39, 432 (2012).

24. D. Pedrazzoli, A. Pegoretti, and K. Kalaitzidou, J. Appl. Polym. Sci., 132, (2015).

25. D. Pedrazzoli, A. Pegoretti, and K. Kalaitzidou, Compos. Sci. Technol., 98, 15 (2014).

26. D. Pedrazzoli and A. Pegoretti, Compos. Part A: Appl. Sci. Manuf., 66, 25 (2014).

27. D. Pedrazzoli and A. Pegoretti, Compos. Sci. Technol., 76, 77 (2013).

28. L.S. Cividanes, E.A.N. Simonetti, M.B. Moraes, F.W. Fernandes, and G.P. Thim, Polym. Eng. Sci., 54, 2461 (2014).

29. A. Allaoui, eXPRESS Polym. Lett., 3, 588 (2009). 